\title{
Value of exercise stress electrocardiography for stratification of exercise capacity and left ventricular systolic and diastolic function on coronary slow flow: case- control study
}

Yonghuai Wang ${ }^{1}$, Jinyang $\mathrm{Li}^{2}$, Shuang $\mathrm{Liu}^{1}$, Lixin $\mathrm{Mu}^{1}$, Guangyuan $\mathrm{Li}^{1}$, Hang Yu${ }^{2}$, Jun Yang ${ }^{1}$ and Chunyan Ma ${ }^{1^{*}}$ (D)

\begin{abstract}
Background: Coronary slow flow phenomenon (CSFP) is an angiographic entity characterized by delayed coronary opacification in absence of evident obstructive lesion in the epicardial coronary artery. However, whether patients with CSFP exhibit differing responses to exercise is still not known. This study aimed to evaluate results of exercise stress electrocardiography (ExECG) and left ventricular (LV) function during exercise, and study the value of ExECG for stratification of exercise capacity and LV function in patients with CSFP.

Methods: Thirty patients with CSFP and 24 controls were enrolled in the study. Diagnosis of CSFP was made by Thrombolysis in Myocardial Infarction frame count. ExECG and LV function measured by echocardiography at rest, during exercise and recovery phase were evaluated.

Results: Negative ExECG was found in 24 (80\%) patients with CSFP. At rest, LV global longitudinal strain (GLS) decreased and mitral average E/e' increased in patients with CSFP compared with controls; however, there were no differences in these parameters between CSFP patients with negative ExECG and patients with positive ExECG. During exercise, CSFP patients with negative ExECG and controls had significantly increased LV GLS and decreased mitral average E/e', but CSFP patients with positive ExECG had significantly decreased LV GLS and increased mitral average E/e'.

Conclusions: About 80\% patients with CSFP exhibited negative ExECG. CSFP patients with negative ExECG exhibited improved LV function but CSFP patients with positive ExECG exhibited impaired LV function during exercise. ExECG may aid in the stratification of exercise capacity and LV function in patients with CSFP.
\end{abstract}

Keywords: Coronary slow flow phenomenon, Exercise stress electrocardiography, Left ventricular function, Echocardiography

\footnotetext{
* Correspondence: cmu1h_mcy@126.com

${ }^{1}$ Department of Cardiovascular Ultrasound, First Hospital of China Medical

University, No. 155 Nanjingbei Street, Shenyang 110001, Liaoning, China

Full list of author information is available at the end of the article
}

(c) The Author(s). 2019 Open Access This article is distributed under the terms of the Creative Commons Attribution 4.0 International License (http://creativecommons.org/licenses/by/4.0/), which permits unrestricted use, distribution, and reproduction in any medium, provided you give appropriate credit to the original author(s) and the source, provide a link to the Creative Commons license, and indicate if changes were made. The Creative Commons Public Domain Dedication waiver (http://creativecommons.org/publicdomain/zero/1.0/) applies to the data made available in this article, unless otherwise stated. 


\section{Background}

Coronary slow flow phenomenon (CSFP) is an angiographic entity characterized by delayed coronary opacification in the absence of an evident obstructive lesion in the epicardial coronary artery [1]. CSFP is not an infrequent finding, with a reported incidence of approximately 1 to $7 \%$ in patients in whom coronary angiography is performed because of suspicious cardiovascular disease [2-4]. Rather than representing a simple angiographic observation, CSFP has been known to be associated with acute myocardial infraction, malignant ventricular fibrillation, or even aborted sudden death [5-7]. Moreover, our previous study revealed that left ventricular (LV) systolic and diastolic functions in patients with CSFP are impaired at rest $[8,9]$. Therefore, patients with CSFP should receive close attention.

CSFP patients may experience recurrent angina, necessitating readmission to the coronary care unit or repeat coronary angiography for an acute exacerbation. However, it has been reported that patients with CSFP may have different kinds of angina [10]. Most patients with CSFP present with angina at rest, but other patients may present with exercise angina or mixed angina [10]. Therefore, we hypothesized that patients with CSFP may have differing results with exercise stress electrocardiography (ExECG). Moreover, whether patients with CSFP exhibit differing responses to exercise in LV function is still not precisely known.

It has been shown that ExECG can privode important value for risk stratification in suspected or known coronary heart disease who can exercise [11-13]. However, whether ExECG can aid in the stratification of exercise capacity and the LV function during exercise is not well understood. Distinguishing patients with CSFP with differing responses to exercise may provide the basis for differential management of these patients.

In view of the foregoing, we aimed to evaluate results of ExECG and LV function during exercise by echocardiography, and investigate the value of ExECG in the stratification of exercise capacity and LV function in patients with CSFP in the present study.

\section{Methods}

\section{Study population}

This was a case-control study performed in the cardiology department of our hospital between December 2017 and November 2018. Subjects were consecutively included in the study and had normal or near-normal ( $<40 \%$ stenosis) coronary arteries on coronary angiography, which was performed because of angina, coronary risk factors or abnormal electrocardiography changes. The CSFP group consisted of individuals with a corrected thrombolysis in myocardial infarction (TIMI) frame count (TFC) exceeding 27 in one or more vessels [14]. The control group consisted of individuals with a corrected TFC not more than 27 in all vessels.

Patients having the following features were excluded: incalculable TFC; coronary artery spasm or ectasia; LV ejection fraction $<52 \%$ in males or $<54 \%$ in females [15]; any arrhythmia (atrioventricular conduction abnormalities, bundle branch block, ventricular preexcitation, atrial fibrillation, or paced rhythm); abnormal heart structure (congenital heart disease, cardiomyopathies, or valvular dysfunction); pericardial disease (pericardial effusion or constrictive pericarditis); previous history of myocardial infarction; uncontrolled hypertension (systolic blood pressure $>160$ $\mathrm{mmHg}$ or diastolic blood pressure $>105 \mathrm{mmHg}$ ); hyperthyroidism; hypothyroidism; malignancy; autoimmune disease; infection; pulmonary, hepatic, and renal disorders; hematological disorders (anemia, bone marrow involved by neoplastic disease, or red blood cell transfusions); and a recent major operation (within 90 days).

All examinations were performed by investigators who had no information about the clinical status of the participants. All concomitant medications were stopped $\geq 12 \mathrm{~h}$ prior to the procedure. Written informed consent was obtained from all participants, and the study protocol was approved by China Medical University Ethics Committee and complied with the ethical guidelines of the 1975 Declaration of Helsinki.

\section{Coronary angiography and TFC calculation}

Coronary angiography was performed using the General Electric Innova 3100 (Milwaukee, WI, USA) by the femoral approach in multiple angulated views. A standard Judkins technique was used in all the studied individuals with $5 \mathrm{~F}$ Judkins catheters, and iohexol $(350 / 100 \mathrm{~mL})$ was used as a contrast agent and manually injected intravenously at the same rate of 3-4 $\mathrm{mL} / \mathrm{s}$ for the left coronary artery and $2-3 \mathrm{~mL} / \mathrm{s}$ for the RCA. TFC was used to quantitatively evaluate flow rates of each major coronary artery, including the left anterior descending artery (LAD), the left circumflex coronary artery (LCX), and the right coronary artery (RCA), according to the method first described by Gibson et al. [14]. TFC, recorded at 30 frames per second, was the number of frames from the second the contrast medium first appeared in the ostium of the coronary artery to the second it reached a distal coronary landmark. Because the LAD is usually longer than the LCX and RCA, the TFC of LAD is divided by 1.7 to obtain the corrected TFC of LAD (cLAD). The mean TFC for each subject was the average of TFC of RCA, LCX, and CLAD. The TFC was undertaken by two separate cardiologists and a third observer resolved any disagreement. 


\section{Seattle angina questionnaire}

Seattle Angina Questionnaire (SAQ) was collected at the time of study enrollment under the supervision of a trained cardiologist to assess symptoms of angina and their impact on quality of life. SAQ is a validated 19-item questionnaire that measures five key domains related to coronary artery disease: physical limitations, angina stability, angina frequency, treatment satisfaction, and quality of life. Scores range from 0 through 100 for all domains. Higher scores indicate fewer physical limitations due to angina, less angina, and better quality of life $[16,17]$.

\section{Exercise stress electrocardiography}

Exercise testing was performed within $72 \mathrm{~h}$ after coronary angiography using standard Bruce protocol according to standard clinical practice. Heart rate and blood pressure were measured, and a 12-lead ECG was taken at rest, at each stage of the exercise protocol, and during recovery ( $\geq 6 \mathrm{~min}$ after exercise). Patients were motivated and encouraged to reach $85 \%$ of maximal predicted heart rate, until they reached an endpoint. Exercise endpoints included physical exhaustion, severe ischemia (severe chest pain, $>2 \mathrm{~mm}$ horizontal or downsloping ST depression), severe hypertension (systolic blood pressure $>240 \mathrm{mmHg}$ or diastolic blood pressure $>110$ $\mathrm{mmHg}$ ), severe hypotension (decrease $>20 \mathrm{mmHg}$ in systolic blood pressure from baseline), significant arrhythmia, or pre-syncope. Rate-pressure product and metabolic equivalents (METs) were recorded. Positive exercise stress ECG was defined as significant chest pain, hypotension, or $\geq 1 \mathrm{~mm}$ planar or downsloping ST depression in two or more leads of the same territory, during exercise or recovery. The results of ExECG were interpreted by two separate experienced cardiologists and a third observer resolved any disagreement.

\section{Resting and exercise stress echocardiography}

According to the recommendations of the American Society of Echocardiography [15], standard echocardiographic examination was performed in the lateral decubitus position using a Vivid E9 ultrasound system (GE Healthcare, Waukesha, WI, USA) equipped with M5S phased-array probe. The two-dimensional cine loops were recorded for offline analysis using an EchoPAC work station (GE Healthcare).

All patients underwent a comprehensive echocardiography at rest. LV ejection fraction was measured by biplane Simpson method. In order to assess LV diastolic function, we measured left atrial (LA) volume index, mitral E, mitral A, mitral septal e', mitral lateral e', and tricuspid regurgitation velocity, and calculated mitral E/A, mitral average E', and mitral average E/e' [18].

Exercise stress echocardiography images were acquired immediately (within 90s) after peak exercise from the second the patients lay in the bed and during recovery ( $\geq 6 \mathrm{~min}$ after exercise). The images included twodimensional images from parasternal long-axis and three apical views (long-axis, four-chambers, and twochambers), mitral valve flow Doppler spectrum, and mitral annular tissue Doppler spectrum. Immediate post-exercise two-dimensional images were obtained using a continuous imaging capture system and the images with best quality were chosen for analysis. Patients with poor imaging quality due to significant respiratory movements immediately after exercise were excluded. LV ejection fraction, LA volume index, mitral E, mitral average e', and mitral average E/ E' were assessed.

Two-dimensional speckle-tracking analysis was performed at rest, in the immediate post-exercise period, and in the recovery phase according to the common standard from the consensus document of the EACVI/ASE/Industry Task Force [19]. After manual delineation of the LV endocardial boundary, the software automatically drew the epicardial boundary. Then the widths of the interesting regions were adjusted manually to match the boundaries of the myocardium. The software automatically tracked speckle patterns during the cardiac cycle and yielded a strain curve of the 18 segments of LV. Patients with inadequate tracking of more than one segment in at least one apical view were excluded from the study. LV global longitudinal strain (GLS) was calculated by averaging end-systolic strain of all LV myocardial segments.

\section{Reproducibility}

Intraobserver and interobserver variabilities for LV GLS in the immediate post-exercise period were examined in 10 randomly selected patients. The same observer who was blinded to the initial measurements repeated the measurements after more than 4 weeks to assess intraobserver variability. A second independent observer repeated the measurements twice to assess interobserver variability.

\section{Statistical analysis}

Normality plots with tests were performed using the Shapiro-Wilk test. Continuous variables were presented as the mean \pm standard deviation (SD) or median (interquartile range) and categorical variables as percentages. Continuous variables were compared using the independent $\mathrm{t}$-test or Mann-Whitney $U$ test, where appropriate. To compare the proportion of categorical variables, chi-square or Fisher exact test was used. Comparisons among $\geq 3$ independent groups were assessed using one-way analysis of variance (ANOVA), and comparisons between groups were performed by post-hoc pairwise comparisons (Scheffe's). Comparisons among $\geq 3$ matching groups were assessed using one-way repeated measures ANOVA, and post-hoc pairwise comparisons (Tukey's) were used to probe significant differences between groups. Intraobserver and interobserver 
variabilities were evaluated by Bland-Altman analysis. For all parameters, $P<0.05$ (two-tailed) was considered statistically significant. All statistical analyses were performed using SPSS 17.0 software package (SPSS version 17, Chicago, IL, USA).

\section{Results}

The study flow chart is shown in Fig. 1. A total of 65 patients were enrolled in the study. Of the 65 patients, we excluded 3 patients who were unable to exercise, 5 patients because of significant respiratory movements in the immediate post-exercise period, and 3 patients because of inadequate tracking during two-dimensional speckle-tracking analysis. The analyzed population consisted of 54 subjects (30 patients with CSFP; 24 control subjects).

The demographic, biochemical data, medications, and angiographic findings of the study population are shown in Table 1 . All of the individuals did not use intracoronary medications. The red cell distribution width value in patients with CSFP was significantly higher than in controls. Patients

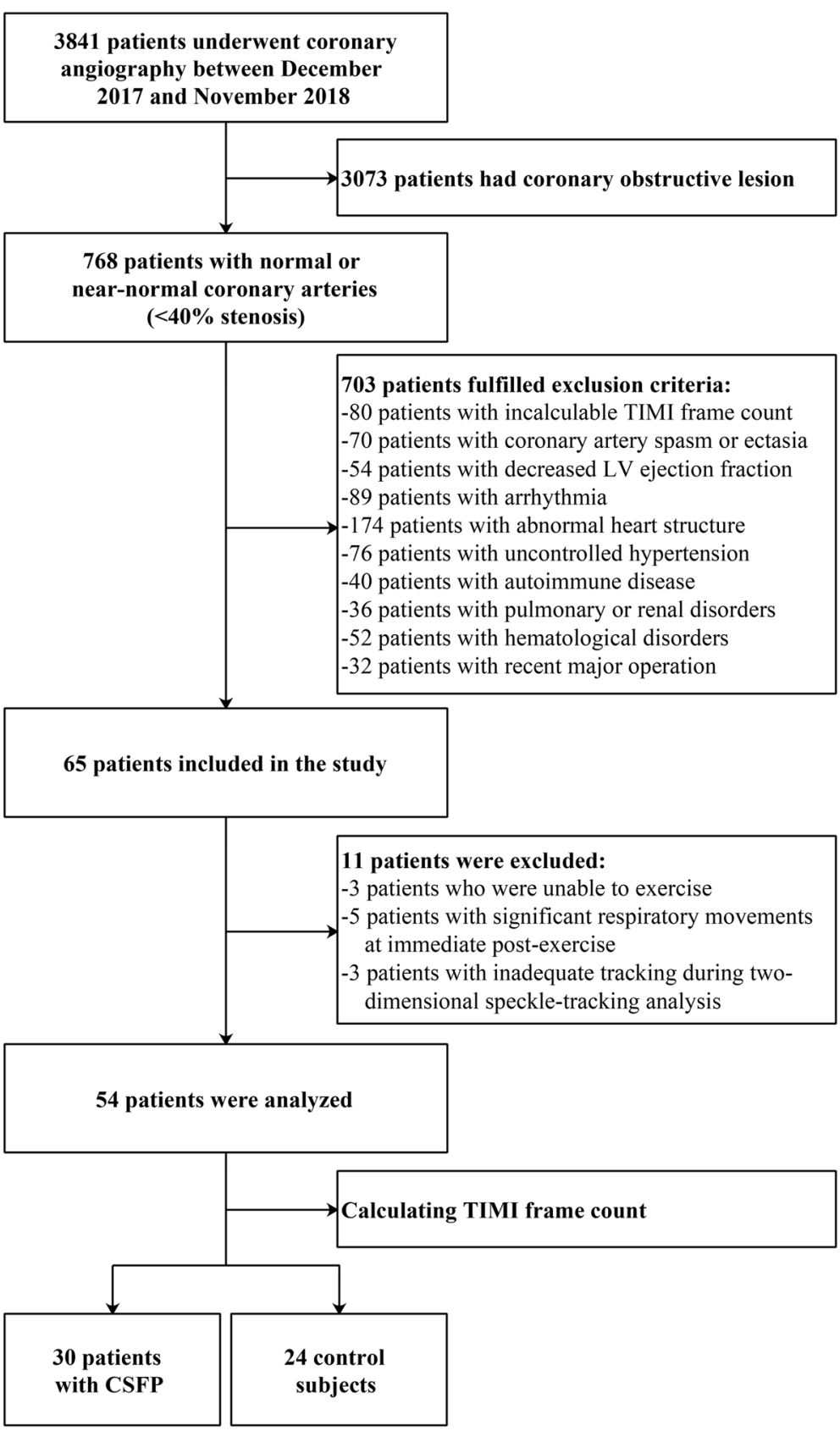

Fig. 1 Patient recruitment flow chart. LV, left ventricle 
Table 1 Comparison of baseline characteristics and angiographic findings

\begin{tabular}{|c|c|c|c|c|}
\hline & Controls $(n=24)$ & $\operatorname{CSFP}(n=30)$ & $\mathrm{OR}[95 \% \mathrm{Cl}]$ & $P$-value \\
\hline \multicolumn{5}{|l|}{ Demographics } \\
\hline Age (yrs) & $54.01 \pm 8.14$ & $56.31 \pm 7.55$ & $1.05[0.99-1.12]$ & 0.09 \\
\hline Male sex $[n(\%)]$ & $12(50 \%)$ & $20(67 \%)$ & $2.00[0.66-6.03]$ & 0.27 \\
\hline $\mathrm{BMI}\left(\mathrm{kg} / \mathrm{m}^{2}\right)$ & $24.72 \pm 3.46$ & $24.13 \pm 3.22$ & $0.90[0.78-1.10]$ & 0.34 \\
\hline Body surface area $\left(\mathrm{m}^{2}\right)$ & $1.75 \pm 0.15$ & $1.73 \pm 0.22$ & $0.92[0.80-1.12]$ & 0.78 \\
\hline \multicolumn{5}{|l|}{ Medical history } \\
\hline Smoking $[n(\%)]$ & $5(21 \%)$ & $11(37 \%)$ & $2.20[0.64-7.56]$ & 0.24 \\
\hline Systolic blood pressure (mmHg) & $127.56 \pm 14.26$ & $125.33 \pm 11.79$ & $1.01[0.98-1.05]$ & 0.39 \\
\hline Diastolic blood pressures (mmHg) & $76.89 \pm 10.06$ & $75.09 \pm 8.90$ & $1.02[0.98-1.07]$ & 0.34 \\
\hline Hypertension [n(\%)] & $11(46 \%)$ & $10(33 \%)$ & $0.59[0.20-1.79]$ & 0.41 \\
\hline Diabetes mellitus [n(\%)] & $3(13 \%)$ & $2(7 \%)$ & $0.50[0.08-3.27]$ & 0.65 \\
\hline Duration of illness (months) & $12.0(5.5-72.0)$ & $16.0(7.0-48.0)$ & $1.00[0.99-1.01]$ & 0.63 \\
\hline \multicolumn{5}{|l|}{ Laboratory values } \\
\hline Triglycerides (mmol/L) & $1.52 \pm 1.00$ & $1.49 \pm 0.80$ & $0.96[0.56-1.67]$ & 0.90 \\
\hline Total cholesterol (mmol/L) & $4.43 \pm 0.82$ & $4.39 \pm 0.76$ & $0.93[0.49-1.75]$ & 0.82 \\
\hline LDL cholesterol (mmol/L) & $2.69 \pm 0.69$ & $2.80 \pm 0.65$ & $1.28[0.61-2.70]$ & 0.52 \\
\hline $\mathrm{HDL}$ cholesterol (mmol/L) & $1.25 \pm 0.31$ & $1.13 \pm 0.32$ & $0.26[0.04-1.63]$ & 0.14 \\
\hline Fasting blood glucose (mmol/L) & $5.36 \pm 0.73$ & $5.54 \pm 0.58$ & $1.52[0.70-3.27]$ & 0.29 \\
\hline Red blood cell count $\left(10^{12} / \mathrm{L}\right)$ & $4.54 \pm 0.37$ & $4.60 \pm 0.44$ & $1.47[0.41-5.21]$ & 0.56 \\
\hline Red cell distribution width (\%) & $12.51 \pm 0.55$ & $12.91 \pm 0.48$ & $6.05[1.52-24.03]$ & 0.004 \\
\hline Platelet count $\left(10^{9} / \mathrm{L}\right)$ & $211.24 \pm 38.83$ & $205.15 \pm 41.13$ & $0.99[0.98-1.01]$ & 0.56 \\
\hline Platelet distribution width (\%) & $12.04 \pm 1.70$ & $12.75 \pm 1.55$ & $1.31[0.95-1.81]$ & 0.09 \\
\hline Total bilirubin $(\mu \mathrm{mol} / \mathrm{L})$ & $11.87 \pm 4.54$ & $10.67 \pm 3.51$ & $0.91[0.82-1.09]$ & 0.12 \\
\hline Uric acid $(\mu \mathrm{mol} / \mathrm{L})$ & $292.76 \pm 82.76$ & $309.47 \pm 64.96$ & $1.01[0.90-1.08]$ & 0.34 \\
\hline Fibrinogen $(\mathrm{g} / \mathrm{L})$ & $3.03 \pm 0.61$ & $2.88 \pm 0.62$ & $0.67[0.29-1.53]$ & 0.34 \\
\hline \multicolumn{5}{|l|}{ Medications } \\
\hline Aspirin [n(\%)] & $5(21 \%)$ & $4(13 \%)$ & $0.58[0.14-2.47]$ & 0.49 \\
\hline ACEI/ARB [n(\%)] & $7(29 \%)$ & $14(47 \%)$ & $2.13[0.68-6.62]$ & 0.26 \\
\hline$\beta$-Blockers $[n(\%)]$ & $13(54 \%)$ & $19(63 \%)$ & $1.46[0.49-4.36]$ & 0.58 \\
\hline Calcium channel blocker [n(\%)] & $15(63 \%)$ & $19(63 \%)$ & $1.04[0.34-3.15]$ & 0.99 \\
\hline Statin $[n(\%)]$ & $7(29 \%)$ & $9(30 \%)$ & $1.04[0.32-3.38]$ & 0.99 \\
\hline Nitrates $[\mathrm{n}(\%)]$ & $15(63 \%)$ & $22(73 \%)$ & $1.65[0.52-5.25]$ & 0.56 \\
\hline Levocarnitine/Trimetazidine [n(\%)] & $12(50 \%)$ & $20(67 \%)$ & $2.00[0.66-6.03]$ & 0.27 \\
\hline \multicolumn{5}{|l|}{ TFC } \\
\hline$C L A D$ & $23.08 \pm 3.55$ & $44.35 \pm 15.41$ & $1.41[1.16-1.73]$ & $<0.001$ \\
\hline LCX & $19.90 \pm 3.90$ & $33.74 \pm 13.86$ & $1.27[1.11-1.44]$ & $<0.001$ \\
\hline RCA & $22.52 \pm 3.68$ & $41.13 \pm 15.50$ & $1.59[1.25-2.03]$ & $<0.001$ \\
\hline Mean & $21.83 \pm 2.54$ & $39.74 \pm 12.40$ & $2.03[1.35-3.06]$ & $<0.001$ \\
\hline
\end{tabular}

Values shown are mean $\pm S D$ or percentages. Abbreviations: $B M I$, body mass index; $L D L$, low-density lipoprotein; $H D L$, high-density lipoprotein; $A C E I$, angiotensinconverting enzyme inhibitor; $A R B$, angiotensin II receptor blocker; TFC, thrombolysis in myocardial infarction frame count; $C L A D$, corrected left anterior descending coronary artery; $L C X$, left circumflex coronary artery; $R C A$, right coronary artery

with CSFP had significantly higher values of TFC for cLAD, LCx, and RCA as well as mean TFC than controls.

All patients and controls reached $85 \%$ of maximal predicted heart rate. There were no significant arrhythmias, syncope, or deaths during exercise. Heart rate and blood pressure at rest and during exercise did not differ between the CSFP patients and controls (Table 2). Chest pain was experienced by 4 (13\%) CSFP patients and by 
Table 2 Comparison of exercise stress electrocardiography parameters

\begin{tabular}{|c|c|c|c|c|}
\hline & $\begin{array}{l}\text { Controls } \\
(n=24)\end{array}$ & $\begin{array}{l}\text { CSFP } \\
(n=30)\end{array}$ & OR $[95 \% \mathrm{Cl}]$ & $P$-value \\
\hline Peak systolic blood pressure $(\mathrm{mmHg})$ & $174.07 \pm 23.23$ & $176.54 \pm 33.20$ & $1.00[0.98-1.02]$ & 0.75 \\
\hline Peak diastolic blood pressure $(\mathrm{mmHg})$ & $146.86 \pm 22.07$ & $148.85 \pm 37.07$ & $1.00[0.98-1.02]$ & 0.81 \\
\hline Peak heart rate (bpm) & $150.57 \pm 7.70$ & $151.85 \pm 9.53$ & $1.02[0.96-1.08]$ & 0.59 \\
\hline Speed (mph) & $4.51 \pm 0.51$ & $4.26 \pm 0.57$ & $2.39[0.85-6.72]$ & 0.09 \\
\hline Grade (\%) & $16.77 \pm 1.27$ & $15.86 \pm 1.80$ & $1.47[1.01-2.15]$ & 0.04 \\
\hline Rate-pressure product $\left(10^{3} \mathrm{bpm} \mathrm{mmHg}\right)$ & $21.40 \pm 3.21$ & $21.33 \pm 3.13$ & $1.00[0.98-1.02]$ & 0.92 \\
\hline METs & $12.16 \pm 1.63$ & $10.78 \pm 2.09$ & $1.52[1.08-2.13]$ & 0.009 \\
\hline ST-segment depression $\geq 1 \mathrm{~mm}[\mathrm{n}(\%)]$ & 0 & $5(17 \%)$ & & 0.04 \\
\hline Angina [n(\%)] & 0 & $4(13 \%)$ & & 0.05 \\
\hline Positive ExECG [n(\%)] & 0 & $6(20 \%)$ & & 0.02 \\
\hline
\end{tabular}

Values shown are mean $\pm S D$. Abbreviations: METs, metabolic equivalents

none of the controls. ST-segment depression occurred in $5(17 \%)$ CSFP patients but not in controls. Both chest pain and ST-segment depression occurred in $3(10 \%)$ CSFP patients. In total, positive ExECG was found in 6 (20\%) CSFP patients and negative ExECG was found in 24 (80\%) CSFP patients. METs were lower in CSFP patients than controls, and CSFP patients with positive ExECG had greater reduction in METs than CSFP patients with negative ExECG (controls, $12.16 \pm 1.63$; CSFP patients with negative ExECG, $11.44 \pm 1.88$; CSFP patients with positive ExECG, $9.12 \pm 2.04, P=0.01$ ).

Differences in the five subscales of the SAQ among groups are shown in Fig. 2. Patients with CSFP had lower scores on each of the SAQ subscales compared with controls, with significant differences on the SAQ-physical limitation scale and SAQ-angina stability scale. CSFP patients with positive ExECG had greater physical limitations than those CSFP patients with negative ExECG.

Comparison of LV function at rest is shown in Table 3. In the LV systolic function analyses, we observed that the LV GLS in CSFP patients was significantly decreased as compared with controls, but there was no difference between CSFP patients with positive and negative ExECG. Moreover, we found that CSFP patients with positive ExECG had significantly decreased mitral E and mitral average e' as compared with CSFP patients with negative ExECG and controls, but there were no differences in mitral average E/e' among groups.

During exercise and recovery phase, no left ventricular wall motion abnormalities were observed in the patients or controls. Mitral E and mitral average e' increased in all patients and controls during exercise. CSFP patients with negative ExECG and controls had significantly increased LV GLS and decreased mitral average E/e', but CSFP patients with positive ExECG had significantly decreased LV GLS and increased mitral average E/e' during exercise (Table 4 and Fig. 3).

Mean difference in intraobserver variability of LV GLS in the immediate post-exercise period was $0.12 \%$ ( $95 \%$ confidence interval [CI]: -0.92 to $1.13 \%)$. Mean difference in interobserver variability was $-0.06 \%$ (95\% CI: 1.35 to $1.23 \%$ ).

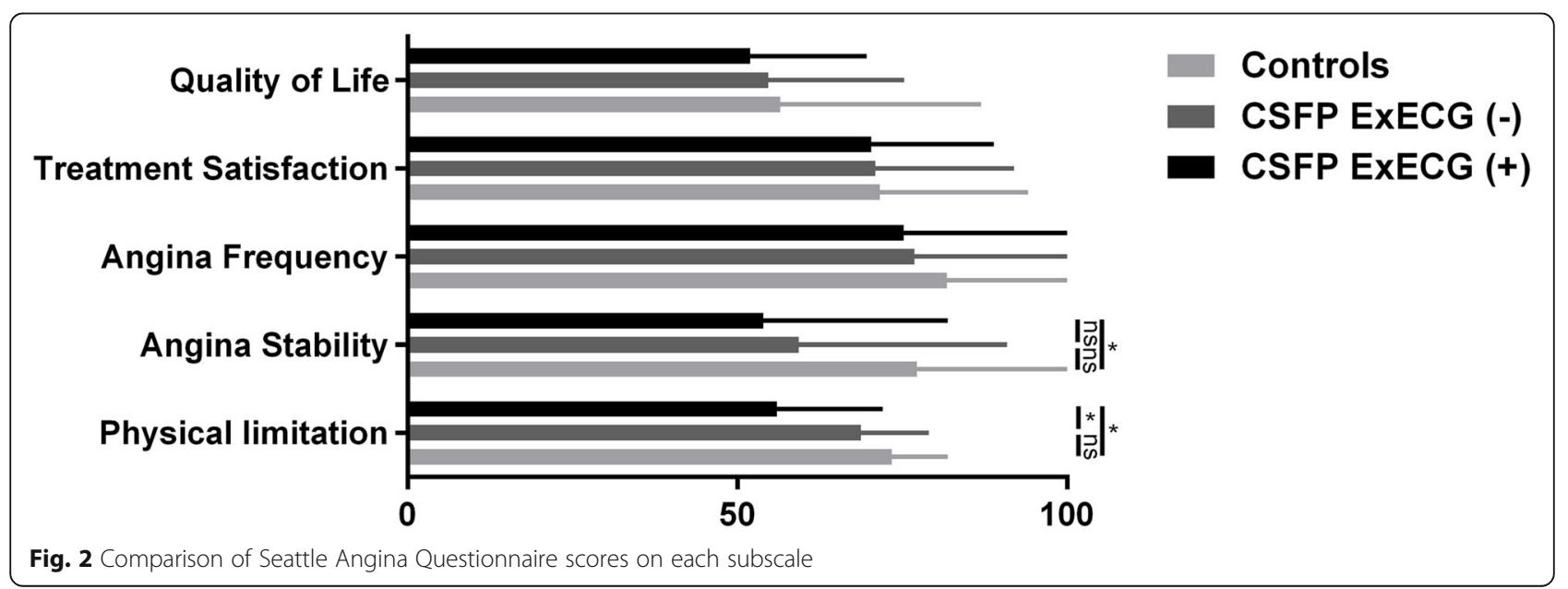


Table 3 Comparison of left ventricular systolic and diastolic function at rest

\begin{tabular}{|c|c|c|c|c|}
\hline & $\begin{array}{l}\text { Controls } \\
(n=24)\end{array}$ & CSFP ExECG $(-)(n=24)$ & CSFP ExECG $(+)(n=6)$ & $P$-value \\
\hline LV end-diastolic diameter (mm) & $47.12 \pm 3.63$ & $47.02 \pm 4.87$ & $47.63 \pm 2.77$ & 0.83 \\
\hline LV end-systolic diameter (mm) & $31.36 \pm 3.51$ & $32.39 \pm 4.13$ & $32.06 \pm 2.80$ & 0.61 \\
\hline LV end-diastolic volume (ml) & $80.30 \pm 15.02$ & $78.60 \pm 13.81$ & $77.52 \pm 18.93$ & 0.78 \\
\hline LV ejection fraction (\%) & $63.00 \pm 4.20$ & $63.20 \pm 3.70$ & $65.00 \pm 4.00$ & 0.15 \\
\hline LV GLS (\%) & $-21.26 \pm 2.74$ & $-19.98 \pm 2.32^{*}$ & $-19.70 \pm 2.38^{*}$ & 0.01 \\
\hline LA volume index $\left(\mathrm{ml} / \mathrm{m}^{2}\right)$ & $27.06 \pm 5.12$ & $29.99 \pm 3.57^{*}$ & $30.56 \pm 5.64^{*}$ & 0.03 \\
\hline Mitral E (cm/s) & $73.85 \pm 16.47$ & $72.34 \pm 16.65$ & $61.72 \pm 15.75^{* \#}$ & $<0.001$ \\
\hline Mitral A (cm/s) & $74.63 \pm 16.81$ & $71.28 \pm 13.33$ & $67.07 \pm 13.59^{*}$ & 0.08 \\
\hline Mitral E/A & $1.12 \pm 0.33$ & $1.09 \pm 0.28$ & $0.94 \pm 0.21^{*}$ & 0.05 \\
\hline Mitral septal e' $(\mathrm{cm} / \mathrm{s})$ & $7.40 \pm 2.05$ & $6.97 \pm 1.76$ & $6.10 \pm 1.74^{*}$ & 0.01 \\
\hline Mitral lateral e' (cm/s) & $10.41 \pm 2.70$ & $9.55 \pm 2.18$ & $8.07 \pm 2.87^{* \#}$ & $<0.001$ \\
\hline Mitral average e' $(\mathrm{cm} / \mathrm{s})$ & $8.94 \pm 2.19$ & $8.26 \pm 1.80$ & $7.09 \pm 2.14^{* \#}$ & $<0.001$ \\
\hline Mitral average E/e' & $8.59 \pm 2.20$ & $8.99 \pm 2.09$ & $9.31 \pm 2.87$ & 0.33 \\
\hline Tricuspid regurgitation velocity $(\mathrm{m} / \mathrm{s})$ & $1.66 \pm 0.69$ & $1.80 \pm 0.54$ & $1.93 \pm 0.59$ & 0.29 \\
\hline
\end{tabular}

Values shown are mean $\pm S D$. Abbreviations: $L V$, left ventricle; $G L S$, global longitudinal strain; $L A$, left atrium; $E$, early diastolic flow velocity; $A$, late diastolic flow velocity; $\mathrm{e}^{\prime}$, early diastolic annular velocity

${ }^{*} P<0.05$ vs. controls; ${ }^{*} P<0.05$ vs. CSFP ExECG (-)

\section{Discussion}

In the present study, we evaluated results of ExECG and LV function during exercise by echocardiography in patients with CSFP, and found that (1) about $80 \%$ of patients with CSFP exhibited negative ExECG and 20\% of patients exhibited positive ExECG; (2) CSFP patients with negative ExECG exhibited improved LV function during exercise but CSFP patients with positive ExECG exhibited impaired LV function; and (3) ExECG can aid in stratification of exercise capacity and LV function in patients with CSFP.

TFC was the only effective and accurate tool for the diagnosis of SCF. Although TFC may be affected by either biologic or technical factors, such as aortic systolic blood pressure, diastolic blood pressures, body surface area, rate of contrast injection or catheter size, we have matche and uniformed the confounders to control the effect on TFC in the study. Currently, the underlying mechanisms of CSFP are not sufficiently clear; they might be related to a chronically elevated resting coronary microvascular resistance resulting from both structural and functional abnormalities [20]. On one hand, endomyocardial biopsies show that there is fibromuscular hyperplasia, myointimal proliferation, mitochondrial abnormalities, endothelial edema, and thickening and degeneration of the coronary microvessels in patients with CSFP $[3,21]$. On the other hand, the elevated resting coronary microvascular resistance may be associated with increased red cell distribution width, which is related to impairments in deformability of erythrocytes and changes in blood rheological properties [22].
Our results show that patients with CSFP exhibit differing responses to exercise as depicted by the results of ExECG and LV function measured by echocardiography. The probable explanation may be the different responses of coronary microvascular resistance to exercise in patients with CSFP. Fineschi et al. [23] quantified coronary microvascular resistances using the thermodilution wire at rest and during hyperemia after injecting papaverine in a patient with CSFP with mainly rest angina, and found that the coronary microvascular resistance at rest was elevated but responses to vasodilator stress was normal. Indeed, our study highlighted improved exercise capacity and LV function during exercise stress in the CSFP patients with negative ExECG.

In addition to CSFP, positive ExECG is also observed in cardiac syndrome $\mathrm{X}$, another clinical entity characterized by angina and normal angiograms. However, syndrome $\mathrm{X}$ is deemed to have a different presentation and pathophysiology compared with CSFP [24]. CSFP is more common in men presenting with rest angina, but syndrome X commonly affects postmenopausal women with exertional angina. In addition, patients with CSFP mainly have elevated resting resistance but preserved coronary flow reserve (CFR); however, patients with syndrome $\mathrm{X}$ have normal resting resistance but reduced CFR [23]. Therefore, although both positive ExECG and normal angiograms are seen in CSFP with positive ExECG and syndrome $\mathrm{X}$, there are essential differences.

ExECG can privode important value for risk stratification in suspected or known coronary heart disease who can exercise, with the advantage of obtaining physiological 
Table 4 Comparison of left ventricular systolic and diastolic function at rest, during exercise, and recovery phase

\begin{tabular}{|c|c|c|c|c|}
\hline & $\begin{array}{l}\text { Controls } \\
(n=24)\end{array}$ & $\operatorname{CSFP} \operatorname{ExECG}(-)(n=24)$ & $\operatorname{CSFP} \operatorname{ExECG}(+)(n=6)$ & $P$-value \\
\hline \multicolumn{5}{|c|}{ LV end-diastolic volume (ml) } \\
\hline Baseline & $85.44 \pm 17.27$ & $76.23 \pm 16.66$ & $76.90 \pm 14.58$ & 0.13 \\
\hline Exercise & $83.87 \pm 17.35$ & $73.96 \pm 19.47$ & $77.06 \pm 15.67$ & 0.22 \\
\hline Recovery & $84.34 \pm 16.61$ & $76.42 \pm 16.87$ & $77.29 \pm 15.54$ & 0.10 \\
\hline$P$-value & 0.84 & 0.82 & 0.96 & \\
\hline \multicolumn{5}{|c|}{ LV ejection fraction (\%) } \\
\hline Baseline & $63.67 \pm 2.37$ & $63.00 \pm 4.00$ & $65.16 \pm 3.39$ & 0.11 \\
\hline Exercise & $68.00 \pm 2.89^{*}$ & $68.50 \pm 3.29^{*}$ & $67.35 \pm 2.24$ & 0.37 \\
\hline Recovery & $64.00 \pm 3.31^{\#}$ & $63.46 \pm 3.88^{\#}$ & $65.00 \pm 2.75$ & 0.30 \\
\hline$P$-value & $<0.001$ & $<0.001$ & 0.09 & \\
\hline \multicolumn{5}{|l|}{ LV GLS (\%) } \\
\hline Baseline & $-21.30 \pm 2.37$ & $-19.77 \pm 2.43$ & $-19.50 \pm 1.13$ & 0.05 \\
\hline Exercise & $-23.18 \pm 2.46^{*}$ & $-23.85 \pm 2.77^{*}$ & $-17.29 \pm 1.76^{*}$ & $<0.001$ \\
\hline Recovery & $-21.00 \pm 1.94^{\#}$ & $-19.17 \pm 2.52^{\#}$ & $-16.84 \pm 1.40^{*}$ & $<0.001$ \\
\hline$P$-value & $<0.001$ & $<0.001$ & 0.02 & \\
\hline \multicolumn{5}{|c|}{ LA volume index $\left(\mathrm{ml} / \mathrm{m}^{2}\right)$} \\
\hline Baseline & $29.24 \pm 7.33$ & $31.08 \pm 5.69$ & $31.53 \pm 6.56$ & 0.73 \\
\hline Exercise & $28.72 \pm 7.58$ & $30.48 \pm 6.21$ & $31.83 \pm 6.11$ & 0.51 \\
\hline Recovery & $29.05 \pm 7.21$ & $30.91 \pm 6.28$ & $31.55 \pm 6.00$ & 0.69 \\
\hline$P$-value & 0.63 & 0.70 & 0.65 & \\
\hline \multicolumn{5}{|c|}{ Mitral E (cm/s) } \\
\hline Baseline & $72.42 \pm 16.79$ & $72.58 \pm 18.10$ & $58.67 \pm 8.96$ & 0.17 \\
\hline Exercise & $95.83 \pm 17.40^{*}$ & $92.08 \pm 30.27^{*}$ & $94.00 \pm 10.32^{*}$ & 0.86 \\
\hline Recovery & $73.83 \pm 14.65^{\#}$ & $65.33 \pm 15.52^{* \#}$ & $62.67 \pm 8.50^{\#}$ & 0.08 \\
\hline$P$-value & $<0.001$ & $<0.001$ & $<0.001$ & \\
\hline \multicolumn{5}{|c|}{ Mitral average e' $(\mathrm{cm} / \mathrm{s})$} \\
\hline Baseline & $8.33 \pm 1.93$ & $7.33 \pm 1.63$ & $7.00 \pm 0.89$ & 0.08 \\
\hline Exercise & $11.75 \pm 2.67^{*}$ & $10.36 \pm 2.19^{*}$ & $9.67 \pm 0.52^{*}$ & 0.06 \\
\hline Recovery & $8.00 \pm 1.77^{\#}$ & $7.92 \pm 1.64^{\#}$ & $8.33 \pm 0.52^{\#}$ & 0.85 \\
\hline$P$-value & $<0.001$ & $<0.001$ & 0.002 & \\
\hline \multicolumn{5}{|c|}{ Mitral average E/e' } \\
\hline Baseline & $9.08 \pm 2.65$ & $8.09 \pm 0.87$ & $7.80 \pm 2.90$ & 0.18 \\
\hline Exercise & $8.52 \pm 2.11$ & $8.70 \pm 2.91$ & $9.79 \pm 1.60^{*}$ & 0.52 \\
\hline Recovery & $9.45 \pm 1.83$ & $8.53 \pm 2.38$ & $7.54 \pm 1.14^{\#}$ & 0.09 \\
\hline$P$-value & 0.31 & 0.37 & 0.02 & \\
\hline
\end{tabular}

Values shown are mean $\pm S D$. Abbreviations: $L V$, left ventricle; $G L S$, global longitudinal strain; $L A$, left atrium; $E$, early diastolic flow velocity; $A$, late diastolic flow velocity; $e^{\prime}$, early diastolic annular velocity

${ }^{*} P<0.05$ vs. baseline; ${ }^{\#} P<0.05$ vs. exercise

exercise data, perceived higher feasibility, and superior cost profile compared with other non-invasive tests [11-13]. However, the application of ExECG in patients with CSFP has not been well investigated and its incremental value is not precisely known. Our study found that $80 \%$ of patients with CSFP exhibited negative ExECG and 20\% of patients exhibited positive ExECG; it further emphasized the incremental value of ExECG for stratification of exercise capacity and LV function. The application of ExECG in patients with CSFP may result in substantial healthcare savings and provide a basis for delivering individualized management to patients.

Unfortunately, there are no standard and effective treatment protocols for patients with CSFP patients, as 


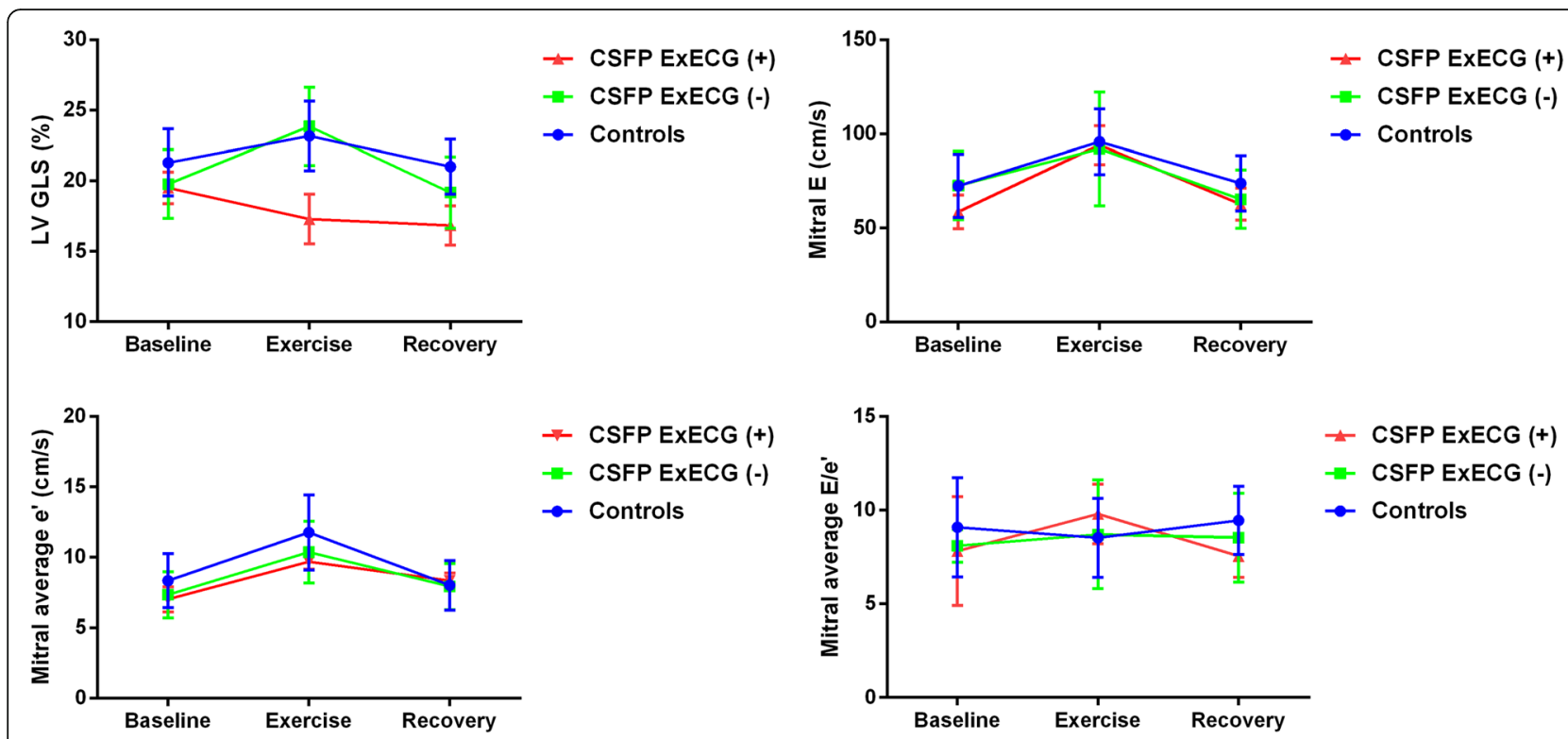

Fig. 3 Comparison of left ventricular systolic and diastolic function at rest, during exercise, and recovery phase. GLS, global longitudinal strain; E, early diastolic flow velocity; $e^{\prime}$, early diastolic annular velocity

of now. Recently, several small studies showed that nebivolol can ameliorate symptoms of patients with CSFP through its beta-receptor blocking activity by inducing endothelium-dependent vasodilatation, but its clinical value is limited $[25,26]$. Our study revealed that CSFP patients with negative ExECG had significantly improved LV function but CSFP patients with positive ExECG had significantly impaired LV function during exercise. These results may shed light on novel therapeutic modalities in patients with CSFP, such as changing physical activity patterns according to stratification of ExECG. CSFP patients with negative ExECG can be motivated and encouraged to take appropriate exercise, but CSFP patients with positive ExECG should be advised to exercise within reasonable limits. However, larger prospective studies are necessary to verify and validate these results in the future.

\section{Study limitations}

Our study has several limitations. First, the image quality during the exercise stress test limited the absolute feasibility for image analysis in our population. Second, the enrollment of patients from a single center might limit the generalizability of our findings. Third, the lack of invasive CFR might limit further study of the association between CFR and LV function during exercise. Fourth, the sample size of the study population may not have been adequate because of the low prevalence of CSFP, and we are now expanding the sample size and performing a followup of these patients.

\section{Conclusions}

About $80 \%$ of patients with CSFP exhibited negative ExECG and 20\% of patients exhibited positive ExECG. CSFP patients with negative ExECG exhibited improved LV function but CSFP patients with positive ExECG exhibited impaired LV function during exercise. ExECG may aid in the stratification of patients with CSFP according to exercise capacity and LV function. Changing physical activity patterns according to stratification of ExECG may be a novel therapeutic direction in patients with CSFP. This is, however, a preliminary study and larger prospective studies are necessary to verify and validate these results.

\section{Abbreviations}

CFR: Coronary flow reserve; CSFP: Coronary slow flow phenomenon; ExECG: Exercise stress electrocardiography; GLS: Global longitudinal strain; LA: Left atrial; LAD: Left anterior descending artery; LCX: Left circumflex coronary artery; LV: Left ventricular; METs: Metabolic equivalents; RCA: Right coronary artery; SAQ: Seattle angina questionnaire; TFC: TIMI frame count; TIMI: Myocardial infarction

\section{Acknowledgements}

The abstract has been accepted by the American Society of Echocardiography 30th Annual Scientifc Sessions (Portland, Oregon, June 21$25,2019)$ and presented as a poster [27].

\section{Authors' contributions}

YHW and CYM analyzed the patient data, and drafted the manuscript. Professor CYM conceived the study. CYM and JY revised the manuscript critically. YHW, JYL, SL, LXM, GYL and HY performed the experiments, data collection and data interpretation. All authors contributed to the study design and all authors read and approved the final manuscript.

\section{Funding}

The design of the study, data collection and data interpretation was supported by the National Natural Science Foundation of China (Project 
number 81871373) and the Youth Project of Basic Scientific Research for Colleges and Universities in Liaoning Province (Project number LQNK201701).

\section{Availability of data and materials}

The datasets generated and analysed during the current study are not publicly available due to a further study of this area but are available from the corresponding author on reasonable request.

\section{Ethics approval and consent to participate}

Written informed consent was obtained from all participants, and the study protocol was approved by the China Medical University Ethics Committee and complied with the ethical guidelines of the 1975 Declaration of Helsinki.

\section{Consent for publication}

Not applicable.

\section{Competing interests}

The authors declare no conflict of interest.

\section{Author details}

'Department of Cardiovascular Ultrasound, First Hospital of China Medical University, No. 155 Nanjingbei Street, Shenyang 110001, Liaoning, China. ${ }^{2}$ Department of Cardiology, First Hospital of China Medical University, Shenyang, Liaoning, China.

Received: 14 August 2019 Accepted: 29 November 2019

\section{Published online: 12 December 2019}

\section{References}

1. Tambe AA, Demany MA, Zimmerman HA, Mascarenhas E. Angina pectoris and slow flow velocity of dye in coronary arteries--a new angiographic finding. Am Heart J. 1972;84:66-71.

2. Singh S, Kothari SS, Bahl VK. Coronary slow flow phenomenon: an angiographic curiosity. Indian Heart J. 2004;56:613-7.

3. Mangieri E, Macchiarelli G, Ciavolella M, Barilla F, Avella A, Martinotti A Dell'Italia LJ, Scibilia G, Motta P, Campa PP. Slow coronary flow: clinical and histopathological features in patients with otherwise normal epicardial coronary arteries. Catheter Cardiovasc Diagn. 1996;37:375-81.

4. Hawkins BM, Stavrakis S, Rousan TA, Abu-Fadel M, Schechter E. Coronary slow flow--prevalence and clinical correlations. Circ J. 2012;76:936-42.

5. Cutri N, Zeitz C, Kucia AM, Beltrame JF. ST/T wave changes during acute coronary syndrome presentation in patients with the coronary slow flow phenomenon. Int J Cardiol. 2011;146:457-8.

6. Wozakowska-Kaplon B, Niedziela J, Krzyzak P, Stec S. Clinical manifestations of slow coronary flow from acute coronary syndrome to serious arrhythmias. Cardiol J. 2009:16:462-8.

7. Saya S, Hennebry TA, Lozano P, Lazzara R, Schechter E. Coronary slow flow phenomenon and risk for sudden cardiac death due to ventricular arrhythmias: a case report and review of literature. Clin Cardiol. 2008;31:352-5.

8. Wang Y, Ma C, Zhang Y, Guan Z, Liu S, Li Y, Yang J. Assessment of left and right ventricular diastolic and systolic functions using two-dimensional speckle-tracking echocardiography in patients with coronary slow-flow phenomenon. PLoS One. 2015;10:e0117979.

9. Wang Y, Ma C, Zhang Y, Guan Z, Liu S, Li Y, Yang J. Layer-specific analysis of left ventricular myocardial contractility in patients with coronary slow-flow phenomenon. J Clin Ultrasound. 2016;44:429-36.

10. Chaudhry MA, Smith M, Hanna EB, Lazzara R. Diverse spectrum of presentation of coronary slow flow phenomenon: a concise review of the literature. Cardiol Res Pract. 2012;2012:383181.

11. Task Force M, Montalescot G, Sechtem U, Achenbach S, Andreotti F, Arden C, Budaj A, Bugiardini R, Crea F, Cuisset T, Di Mario C, Ferreira JR, Gersh BJ, Gitt AK, Hulot JS, Marx N, Opie LH, Pfisterer M, Prescott E, Ruschitzka F, Sabate M, Senior R, Taggart DP, van der Wall EE, Vrints CJ, Guidelines ESCCfP, Zamorano JL, Achenbach S, Baumgartner $H$, Bax J, Bueno $H$, Dean V, Deaton C, Erol C, Fagard R, Ferrari R, Hasdai D, Hoes AW, Kirchhof $P$, Knuuti J, Kolh $P$, Lancellotti $P$, Linhart A, Nihoyannopoulos P, Piepoli MF, Ponikowski P, Sirnes PA, Tamargo JL, Tendera M, Torbicki A, Wijns W, Windecker S, Document R, Knuuti J, Valgimigli M, Bueno H, Claeys MJ, Donner-Banzhoff N, Erol C, Frank H, Funck-Brentano C, Gaemperli O, Gonzalez-Juanatey JR, Hamilos M, Hasdai D, Husted S, James SK, Kervinen K, Kolh P, Kristensen SD,
Lancellotti P, Maggioni AP, Piepoli MF, Pries AR, Romeo F, Ryden L, Simoons ML, Sirnes PA, Steg PG, Timmis A, Wijns W, Windecker S, Yildirir A, Zamorano JL. 2013 ESC guidelines on the management of stable coronary artery disease: the Task Force on the management of stable coronary artery disease of the European Society of Cardiology. Eur Heart J. 2013;34:2949-3003.

12. Fihn SD, Blankenship JC, Alexander KP, Bittl JA, Byrne JG, Fletcher BJ, Fonarow GC, Lange RA, Levine GN, Maddox TM, Naidu SS, Ohman EM, Smith PK. 2014 ACC/AHA/AATS/PCNA/SCAI/STS focused update of the guideline for the diagnosis and management of patients with stable ischemic heart disease: a report of the American College of Cardiology/ American Heart Association Task Force on Practice Guidelines, and the American Association for Thoracic Surgery, Preventive Cardiovascular Nurses Association, Society for Cardiovascular Angiography and Interventions, and Society of Thoracic Surgeons. J Am Coll Cardiol. 2014;64:1929-49.

13. Bourque JM, Beller GA. Value of exercise ECG for risk stratification in suspected or known CAD in the era of advanced imaging technologies. JACC Cardiovasc Imaging. 2015:8:1309-21.

14. Gibson CM, Cannon CP, Daley WL, Dodge JT Jr, Alexander B Jr, Marble SJ, McCabe CH, Raymond L, Fortin T, Poole WK, Braunwald E. TIMI frame count: a quantitative method of assessing coronary artery flow. Circulation. 1996; 93:879-88.

15. Lang RM, Badano LP, Mor-Avi V, Afilalo J, Armstrong A, Ernande L, Flachskampf FA, Foster E, Goldstein SA, Kuznetsova T, Lancellotti P, Muraru D, Picard MH, Rietzschel ER, Rudski L, Spencer KT, Tsang W, Voigt JU. Recommendations for cardiac chamber quantification by echocardiography in adults: an update from the American Society of Echocardiography and the European Association of Cardiovascular Imaging. J Am Soc Echocardiogr. 2015;28:1-39 e14.

16. Spertus JA, Winder JA, Dewhurst TA, Deyo RA, Prodzinski J, McDonell M, Finn SD. Development and evaluation of the Seattle angina questionnaire: a new functional status measure for coronary artery disease. J Am Coll Cardiol. 1995;25:333-41.

17. Chan PS, Jones PG, Arnold SA, Spertus JA. Development and validation of a short version of the Seattle angina questionnaire. Circulation. Cardiovasc Qual Outcomes. 2014;7:640-7.

18. Nagueh SF, Smiseth OA, Appleton CP, Byrd BF 3rd, Dokainish $H_{\text {, }}$ Edvardsen T, Flachskampf FA, Gillebert TC, Klein AL, Lancellotti $P$, Marino P, Oh JK, Popescu BA, Waggoner AD. Recommendations for the evaluation of left ventricular diastolic function by echocardiography: an update from the American Society of Echocardiography and the European Association of Cardiovascular Imaging. J Am Soc Echocardiogr. 2016;29:277-314.

19. Voigt JU, Pedrizzetti G, Lysyansky P, Marwick TH, Houle H, Baumann R, Pedri S, Ito Y, Abe Y, Metz S, Song JH, Hamilton J, Sengupta PP, Kolias TJ, d'Hooge J, Aurigemma GP, Thomas JD, Badano LP. Definitions for a common standard for 2D speckle tracking echocardiography: consensus document of the EACVI/ASE/industry Task Force to standardize deformation imaging. Eur Heart J Cardiovasc Imaging. 2015;16:1-11.

20. Wang $X$, Nie SP. The coronary slow flow phenomenon: characteristics, mechanisms and implications. Cardiovasc Diagn Ther. 2011:1:37-43

21. Mosseri M, Yarom R, Gotsman MS, Hasin Y. Histologic evidence for smallvessel coronary artery disease in patients with angina pectoris and patent large coronary arteries. Circulation. 1986;74:964-72.

22. Akpinar I, Sayin MR, Gursoy YC, Aktop Z, Karabag T, Kucuk E, Sen N, Aydin M, Kiran S, Buyukuysal MC, Haznedaroglu IC. Plateletcrit and red cell distribution width are independent predictors of the slow coronary flow phenomenon. J Cardiol. 2014;63:112-8.

23. Fineschi M, Gori T. Coronary slow flow: description of a new "cardiac Y" syndrome. Int J Cardiol. 2009;137:308-10.

24. Agrawal S, Mehta PK, Bairey Merz CN. Cardiac Syndrome X: update 2014. Cardiol Clin. 2014;32:463-78.

25. Gunes $Y$, Tuncer M, Guntekin U, Ceylan Y, Sahin M, Simsek H. Regiona functions of the left ventricle in patients with coronary slow flow and the effects of nebivolol. Ther Adv Cardiovasc Dis. 2009:3:441-6.

26. Albayrak S, Ordu S, Yuksel H, Ozhan H, Yazgan O, Yazici M. Efficacy of nebivolol on flow-mediated dilation in patients with slow coronary flow. Int Heart J. 2009;50:545-53. 
27. Wang Y, Li J, Liu S, Mu L, Li G, Zhao C, Yu H, Yang J, Ma C. 2019 ASE 30th annual scientific sessions-value of treadmill exercise echocardiography combined with stress electrocardiography for Stratifcation of left ventricular systolic and diastolic function in patients with coronary slow flow. J Am Soc Echocardiogr. 2019;32:B115.

\section{Publisher's Note}

Springer Nature remains neutral with regard to jurisdictional claims in published maps and institutional affiliations.

Ready to submit your research? Choose BMC and benefit from:

- fast, convenient online submission

- thorough peer review by experienced researchers in your field

- rapid publication on acceptance

- support for research data, including large and complex data types

- gold Open Access which fosters wider collaboration and increased citations

- maximum visibility for your research: over $100 \mathrm{M}$ website views per year

At $\mathrm{BMC}$, research is always in progress.

Learn more biomedcentral.com/submissions 